\title{
Madeiras utilizadas na fabricação de arcos para instrumentos de corda: aspectos anatômicos
}

\author{
Veronica Angyalossy ${ }^{1}$, Erika Amano ${ }^{1}$ e Edenise Segala Alves ${ }^{2,3}$
}

Recebido em 15/09/2004. Aceito em 27/04/2005

\begin{abstract}
RESUMO - (Madeiras utilizadas na fabricação de arcos para instrumentos de corda: aspectos anatômicos). A madeira de pau-brasil (Caesalpinia echinata Lam.) é mundialmente empregada na confecção de arcos para instrumentos de corda, uma vez que apresenta características únicas de ressonância, densidade, durabilidade, beleza, entre outras qualidades, que a tornam ideal para tal uso. Diferentes amostras de pau-brasil, contudo, fornecem arcos com qualidades distintas. No comércio nacional outras madeiras estão sendo empregadas na produção de arcos. Realizou-se, neste estudo, uma análise qualitativa e quantitativa de diferentes amostras de pau-brasil com o objetivo de apontar diferenças na estrutura da madeira que possam contribuir para o entendimento das causas da variação na qualidade do arco, além da análise de outras espécies objetivando determinar, do ponto de vista estrutural, semelhanças ou diferenças com o paubrasil. Conclui-se que variações no diâmetro dos vasos, distribuição e quantidade de parênquima axial e orientação dos elementos axiais e radiais são parâmetros que devem ser considerados quando se busca determinar as causas das diferenças na qualidade dos arcos de paubrasil. Constatou-se que arcos de boa qualidade apresentam grã linheira e textura fina. Esta última característica decorre da menor proporção de vasos cujo diâmetro é reduzido, raios homogêneos e fibras com paredes espessas e/ou muito espessas. Assim, a relação entre a estrutura e a qualidade do arco está diretamente relacionada com as dimensões, a distribuição e a proporção das células do lenho.
\end{abstract}

Palavras-chave : anatomia da madeira, arcos para violino, Caesalpinia echinata, pau-brasil, madeiras substitutas

\begin{abstract}
Anatomical features of woods used in the manufacture of bows for stringed instruments). Pernambuco wood ( Caesalpinia echinata Lam.) has special characteristics like resonance, density, durability, and beauty; for this reason, it is considered the best material for stringed instruments bows. Besides pernambuco wood has been used around the world, some samples, and consequently some bows, are better than others. In Brazil, others woody species have been used in the manufacture of bows. In this paper some wood samples of pernambuco wood were analysed in order to verify if it is possible to find differences in their anatomical qualitative and quantitative characteristics that explain the bow quality. The comparative analysis of pernambuco wood samples showed variations in vessel diameter, quantity and distribution of axial parenchyma and orientation of axial and radial wood elements.
\end{abstract}

Key words: wood anatomy, violin bow, Caesalpinia echinata, pernambuco wood, alternative woods

\section{Introdução}

A madeira de pau-brasil (Caesalpinia echinata Lam.) é extensivamente procurada no exterior, sendo considerada internacionalmente a única que reúne características ideais de ressonância, densidade, durabilidade, beleza, além da extensão da curvatura, do peso, da espessura e de preciosas qualidades tonais, para a confecção dos melhores arcos de instrumentos de corda (Pierce 2002; Bueno 2002). Segundo Bueno (2002), ela vem sendo extraída ilegalmente e exportada sob a denominação de "pernambuco wood".

A denominação vulgar "pau-brasil", segundo Mainieri (1960), é utilizada em nosso país para designar quatro gêneros diferentes de plantas produtoras de madeira, reunindo erroneamente sob o mesmo nome, madeiras que apresentam coloração avermelhada, a saber Brosimum paraense Huber (Moraceae), Colubrina rufa Reiss e Rhamnidium glabrum Reiss (Rhamnaceae) e três espécies de Sickingia (Willd.) (Rubiaceae).

No caso do pau-brasil verdadeiro (C. echinata), o cerne é alaranjado, bastante evidente na árvore recém cortada, decorrente da presença de brasilina $\left(\mathrm{C}_{16} \mathrm{H}_{14} \mathrm{O}_{5}\right)$, que oxida com a exposição ao ar, assumindo coloração vermelho-coral (Mainieri et al. 1983).

De acordo com Lewis (1998), C. echinata não é classificada em táxons infra-específicos, embora

\footnotetext{
1 Universidade de São Paulo, Instituto de Biociências, Departamento de Botânica, C. Postal 1146, CEP 05422-970, São Paulo, SP, Brasil (vangyalossy@ib.usp.br). Bolsista do CNPq

2 Instituto de Botânica, Seção de Anatomia, Av. Miguel Estéfano, 3687, CEP 004301-012, São Paulo, SP, Brasil. Bolsista do CNPq

3 Autor para correspondência: ealves@ibot.sp.gov.br
} 
muitas populações mostrem diferenças marcantes no tamanho e na forma dos folíolos, na cor da madeira e no hábito. Três diferentes grupos de C. echinata estão sendo estudados por especialistas brasileiros e no futuro talvez a espécie possa ser separada em subespécies ou variedades. $\mathrm{O}$ grupo mais comum apresenta comparativamente os menores folíolos e cerne de coloração alaranjada, sendo encontrado em muitas localidades ao longo da costa brasileira. O segundo grupo difere pouco do primeiro, apresentando, contudo, folíolos um pouco maiores e cerne com coloração laranja avermelhado. Deste morfotipo são conhecidos apenas representantes cultivados nos Estados do Rio de Janeiro e Espírito Santo. O terceiro grupo apresenta folíolos muito grandes e cerne vermelho escuro, sendo encontrados naturalmente, até o momento, apenas em uma localidade na Bahia.

Apesar do consenso entre produtores de que o pau-brasil é a melhor madeira para a fabricação de arco, Matsunaga et al. (1996) informam que, até o momento, não existem publicações científicas que esclareçam por que o pau-brasil é tão apropriado para tal finalidade. A seleção da espécie está baseada na experiência tanto de arqueteiros como músicos, sendo a mesma utilizada há mais de 200 anos.

De acordo com Retford (1964), a manufatura de arcos como arte especializada teve sua origem no século XVIII, na França, na oficina de Tourte "O Velho". Aparentemente pouco se sabe dos seus predecessores; há poucos registros dos primórdios da história do arco e sua origem precisa é desconhecida; os registros mais antigos vêm da cultura árabe e bizantina e datam do século X. Com relação às madeiras empregadas, Pierce (2002) informa que antes da metade do século XVIII eram usadas várias espécies tropicais, incluindo o paubrasil. Segundo Richter (1988), o pau-brasil já era conhecido no mercado europeu por volta de 1550 , quando os primeiros violinos, com a forma dos utilizados atualmente, foram construidos por G. Bartoletti de Saulo, em Bréscia na Itália. Entretanto, foram os irmãos Tourte, em Paris, que consagraram o pau-brasil como material ideal para a confecção de arcos.

Segundo Matsunaga et al. (1996), as propriedades vibracionais da madeira são fundamentais para qualificála como apropriada para a manufatura de instrumentos musicais. Embora os arcos de instrumentos de corda não produzam o som, as propriedades vibracionais da madeira também são muito importantes na determinação da sua qualidade.

Embora a madeira do pau-brasil reúna as propriedades ideais para a confecção de arcos, os produtos resultantes da manufatura de diferentes amostras apresentam qualidades distintas. Com o pau-brasil podem ser confeccionados arcos de alto valor e grande qualidade, até arcos de baixo custo utilizados por amadores e estudantes (Lombardi, www.lombardiarcos.com). As causas dessa variação estão sendo investigadas e parecem ser decorrentes de um conjunto de fatores que envolve a organização estrutural da madeira e aspectos relacionados às suas propriedades químicas e físicas.

A investigação qualitativa e quantitativa de diferentes amostras de pau-brasil poderá ajudar a explicar as causas das diferenças na qualidade dos arcos. Além disso, como no mercado nacional estão sendo introduzidos e, bem aceitos, arcos produzidos com outras madeiras (D. Lombardi, comunicação pessoal), o estudo da estrutura das mesmas poderá ajudar no estabelecimento de características anatômicas envolvidas na melhor qualidade do arco.

O presente estudo objetiva determinar as variações estruturais existentes entre amostras de pau-brasil que possam interferir na qualidade do arco e indicar características desejáveis em outras espécies.

\section{Material e métodos}

Na Tab. 1 estão listadas as espécies examinadas, de acordo com a família, número da coleção de madeira (xiloteca), procedência e nome comercial.

Foram examinadas sete amostras de madeira de pau-brasil (Caesalpinia echinata Lam.). Destas, três (SPw 1968, 1969, 1970) foram coletadas em discos retirados do tronco a 1,30 m do solo. As árvores foram removidas obedecendo a plano de manejo, visando aumento na produção de sementes, na Reserva Biológica e Estação Experimental de Mogi-Guaçu (SP). $\mathrm{O}$ arboreto experimental foi plantado na década de 1970 e conta com aproximadamente 300 árvores (Aguiar \& Pinho 1996). As árvores têm, atualmente, cerca de $10 \mathrm{~m}$ alt. e $15-20 \mathrm{~cm}$ diâm. Segundo Vuono et al. (1986), a região $\left(22^{\circ} 16^{\prime} \mathrm{S}\right.$ e $\left.47^{\circ} 11^{\prime} \mathrm{W}\right)$ apresenta a estação seca e mais fria de abril a setembro e outra úmida e quente de outubro a março, com precipitação pluviométrica anual média de $1.380 \mathrm{~mm}$ e temperatura média anual de $20,4{ }^{\circ} \mathrm{C}$.

A amostra SPw 1978 foi coletada em Porto Seguro (BA), com o auxilio de serrote e formão na região do tronco a 1,30 m do solo, em área de ocorrência natural, de uma árvore com cerca de $60 \mathrm{~cm}$ diâm. A região $\left(14^{\circ} 80^{\prime} \mathrm{S}\right.$ e $\left.39^{\circ} 07^{\prime} \mathrm{W}\right)$ apresenta clima quente e super 
Tabela 1. Relação das madeiras analisadas de acordo com a família, número da coleção de madeira (xiloteca), procedência e nome comercial.

\begin{tabular}{|c|c|c|c|}
\hline Família/Nome científico & Xiloteca, $\mathrm{n}$. & Procedência & Nome comercial \\
\hline $\begin{array}{l}\text { LEGUMINOSAE } \\
\quad \text { Caesalpinia echinata Lam. }\end{array}$ & $\begin{array}{l}\text { SPw } 1978 \\
\text { SPw } 1970 \\
\text { SPw } 1969 \\
\text { SPw } 1968 \\
\text { SPw } 2035 \\
\text { SPw } 2036 \\
\text { SPw } 2037\end{array}$ & $\begin{array}{l}\text { Ilhéus, BA* } \\
\text { Mogi-Guaçu, SP** } \\
\text { Mogi-Guaçu, SP** } \\
\text { Mogi-Guaçu, SP** } \\
\text { Arco de violino } \\
\text { Arco de violino } \\
\text { Arco de violino }\end{array}$ & $\begin{array}{l}\text { pau-brasil, pau-pernambuco, } \\
\text { pernambuco wood }\end{array}$ \\
\hline Caesalpinia ferrea Mart. & $\begin{array}{l}\text { BCTw } 12733 \\
\text { BCTw } 18772\end{array}$ & $\begin{array}{l}\text { Rio Grande no Norte } \\
\text { Paraíba }\end{array}$ & $\begin{array}{l}\text { pau-ferro } \\
\text { coração-de-negro }\end{array}$ \\
\hline Swartzia aptera D.C. & MADw 22714 & Amapá & gombeira, coração-de-negro \\
\hline Swartzia laxiflora Bongard ex Benth. & $\begin{array}{l}\text { MADw } 31320 \\
\text { SPw } 2038\end{array}$ & $\begin{array}{l}\text { Amazonas } \\
\text { Arco de violino }\end{array}$ & $\begin{array}{l}\text { gombeira, } \\
\text { coração-de-negro }\end{array}$ \\
\hline Zollernia paraensis Huber & $\begin{array}{l}\text { MAD-SJRw } 5952 \\
\text { BCTw } 13741 \\
\text { BCTw } 15931\end{array}$ & $\begin{array}{l}\text { Pará } \\
\text { Maranhão } \\
\text { Maranhão }\end{array}$ & $\begin{array}{l}\text { pau-santo, } \\
\text { coração-de-negro, } \\
\text { muirapinima-preta }\end{array}$ \\
\hline \multicolumn{4}{|l|}{ MORACEAE } \\
\hline Brosimum guianense (Aubl.) Huber & $\begin{array}{l}\text { BCTw } 9 \\
\text { SPw } 2040\end{array}$ & $\begin{array}{l}\text { Pará } \\
\text { Arco de violino }\end{array}$ & $\begin{array}{l}\text { pau-cobra, } \\
\text { muirapinima }\end{array}$ \\
\hline Brosimum paraense Huber & BCTw 9225 & $\begin{array}{l}\text { Maranhão } \\
\text { Arco de violino }\end{array}$ & $\begin{array}{l}\text { pau-rainha, } \\
\text { conduru, muirapiranga, } \\
\text { falso-pau-brasil }\end{array}$ \\
\hline Brosimum rubescens Taub. (Satiné) & SPw 2039 & Arco de violino & $\begin{array}{l}\text { pau-rainha, conduru, } \\
\text { muirapiranga, falso-pau-brasil }\end{array}$ \\
\hline $\begin{array}{l}\text { SAPOTACEAE } \\
\quad \text { Manilkara elata (Fr. All.) Monac. }\end{array}$ & BCTw 11534 & Espírito Santo & maçaranduba, parajú \\
\hline
\end{tabular}

$\mathrm{BCTw}=$ Xiloteca Dr. Calvino Mainieri, Instituto de Pesquisas Tecnológicas do Estado de São Paulo S.A. - IPT; SPw = Xiloteca do Herbário Maria Eneida P. Kauffmann Fidalgo, Instituto de Botânica de São Paulo; MADw = U.S. Forest Products Laboratory, Madison; MAD-SJRw= Record Collection - U.S. Forest Products Laboratory, Madison. $*=$ espécime nativo, $* *=$ espécimes reflorestados.

úmido durante todo o ano (Nimer 1989), com precipitação pluviométrica anual média de $2.043 \mathrm{~mm}$ e mensal de $186 \mathrm{~mm}$ e temperatura média anual de $24,3^{\circ} \mathrm{C}$.

As três amostras restantes (SPw 2035, 2036 e 2037), de procedência indeterminada, foram doadas pelo arqueteiro Daniel Lombardi, que as utilizou na confecção de $\operatorname{arcos}$ (Fig. 1).

As oito espécies restantes, listadas na Tab. 1, foram indicadas por arqueteiros, por meio de seu nome comercial, como madeiras que estão sendo utilizadas na confecção de arcos. Amostras destas madeiras foram fornecidas pelo arqueteiro Daniel Lombardi, sendo que a identificação da espécie foi realizada utilizando-se o acervo da Xiloteca Dr. Calvino Mainieri, do Instituto de Pesquisas Tecnológicas do Estado de São Paulo S.A. (IPT).

As amostras de madeiras doadas pelo arqueteiro Daniel Lombardi foram registradas na Xiloteca do Herbário Maria Eneida P. Kauffmann Fidalgo (SPw) do Instituto de Botânica e estão indicadas na Tab. 1 como procedentes de arco de violino. Outras amostras foram obtidas nos acervos da Xiloteca Dr. Calvino Mainieri (BCTw) do Instituto de Pesquisas Tecnológicas de São Paulo e da Xiloteca do United State Forest Products Laboratory - Madison (MADw e MARSJRw).

As lâminas histológicas do lenho disponibilizadas para estudo pelas xilotecas acima mencionadas, bem como as confeccionadas a partir das amostras das árvores coletadas e dos arcos de violino, foram preparadas de acordo com a metodologia usual empregada em anatomia da madeira (Johansen 1940). As superficies longitudinais das madeiras analisadas foram polidas e escaneadas.

As descrições das madeiras seguem a recomendação do IAWA Committee (1989). Os dados quantitativos, referentes ao diâmetro e freqüência dos vasos, estão baseados em 30 medições, utilizando-se Eckblad (1991) para confirmar o tamanho da amostragem. Para estas características é apresentada a 
média das médias dos indivíduos analisados, bem como os valores mínimo e máximo, que correspondem ao menor e ao maior valor obtido dentro dos espécimes de cada táxon analisado.

Na classificação das fibras levou-se igualmente em consideração as recomendações do IAWA Committee (1989), que definem fibras espessas como aquelas cujo lume é observável, apresentando-se menor que três vezes o dobro da parede e fibras muito espessas aquelas cujo lume é quase completamente fechado.

\section{Resultados}

Os arcos de violino confeccionados com pau-brasil (Caesalpinia echinata) (Fig. 1), tem coloração alaranjada do cerne, também evidenciada na Fig. 3. As outras espécies que estão sendo utilizadas na produção de arcos, duas delas indicadas na Fig. 2, são observadas quanto à sua cor nas Fig. 4-9. Observa-se que as madeiras de pau-rainha (Brosimum paraense, $B$. rubescens) e pau-cobra (Brosimum guianense), apresentam, respectivamente, uma coloração avermelhada (Fig. 2a, 8) e avermelhada escura com manchas enegrecidas (Fig. 2b, 7), desenho este que lhe sugere o nome comercial. As outras madeiras apresentam uma coloração enegrecida, recebendo a denominação vulgar de coração de negro, correspondendo, entretanto, a diferentes espécies: pau-ferro (Caesalpinia ferrea Mart. - Fig. 4), gombeira (Swartzia aptera D.C. (Fig. 5) e S. laxiflora Bongard ex Benth.) e pau-santo (Zollernia paraensis Huber - Fig. 6). Por último, a maçaranduba (Manilkara elata) apresenta cerne de coloração castanha-escura (Fig. 2c, 9).

As características anatômicas mais importantes de Caesalpinia echinata e das outras madeiras utilizadas na confecção de arcos estão sumarizadas na Tab. 2. Uma descrição anatômica destas madeiras é apresentada a seguir.

Caesalpinia echinata (pau-brasil) - Cerne alaranjado (Fig. 1 e 3). Grã direita ou linheira (Fig. 19) a irregular (Fig. 20). Camadas de crescimento delimitadas por finas linhas de parênquima marginal com 1 a 2 células de largura (Fig. 10-12), que tangenciam as faixas de parênquima quando presentes (Fig. 13-14). Vasos (Fig. 10-14) solitários e múltiplos de 2 a 4; obstruídos por óleo-resina; (50-)90(-138) $\mu \mathrm{m}$ diâm. tangencial; (10-)23(-33) por $\mathrm{mm}^{2}$; placa de perfuração simples. Fibras de paredes espessas a muito espessas. Parênquima aliforme confluente formando faixas largas, com até 11 células de largura, no espécime nativo procedente da Bahia (SPw 1978 - Fig. 10) e nas amostras de arco de violino SPw 2036 e 2037 (Fig. 1314); nos espécimes de reflorestamento de São Paulo (SPw 1968, 1969, 1970 - Fig. 11) e na amostra de arco de violino SPw 2035 (Fig. 12) o parênquima é predominantemente aliforme, formando pequenas confluências. Raios homogêneos (Fig. 15-16, 19-20); bisseriados (Fig. 15-16); a estratificação (Fig. 15) é observada nas amostras SPw 2036 e 2037, sendo irregular em SPw 2035 e ausente tanto nos espécimes de reflorestamento (São Paulo, SPw 1968, 1969, 1970) quanto no nativo (Bahia, SPw 1978 - Fig. 16). Cristais prismáticos, em células subdivididas do parênquima axial, estão presentes em todas as amostras analisadas, variando, entretanto, em quantidade: abundantes, em SPw 2035 e 1978 (Fig. 18), a escassos em SPw 1968, 1969 e 1970 (Fig. 17); eventualmente são observados em células normais do parênquima radial.

Caesalpinia ferrea (pau-ferro) - Cerne enegrecido, de aspecto fibroso atenuado (Fig. 4). Camadas de crescimento demarcadas por finas linhas de parênquima marginal (Fig. 21). Vasos (Fig. 21) solitários e múltiplos de 2 a 3; obstruídos por óleo-resina; (34-)66(-72) $\mu \mathrm{m}$ de diâmetro tangencial; (5-)11(-19) por $\mathrm{mm}^{2}$; placa de perfuração simples. Fibras de paredes espessas a muito espessas. Parênquima aliforme confluente, predominantemente em faixas (Fig. 21). Raios bisseriados, homogêneos e estratificados (Fig. 22). Cristais prismáticos são abundantes nas células subdivididas do parênquima axial (Fig. 23).

Swartzia aptera, Swartzia laxiflora (gombeira)-Cerne enegrecido, de aspecto fibroso atenuado (Fig. 5). Camadas de crescimento demarcadas por finas linhas de parênquima marginal (Fig. 26). Vasos (Fig. 24, 26) solitários e múltiplos de 2 a 3; obstruídos por óleoresina; (80-)106(-124) $\mu \mathrm{m}$ diâm. tangencial em $S$. aptera e (94-)177(-222) $\mu \mathrm{m}$ em S. laxiflora; (11-)17(-30) por $\mathrm{mm}^{2} \mathrm{em}$ S. aptera e (1-)4(-8) em S. laxiflora; placa de perfuração simples. Fibras de paredes espessas (S. aptera) a muito espessas (S. laxiflora). Parênquima aliforme confluente, predominantemente em linhas com 2 a 3 células de largura (Fig. 24, 26). Raios bisseriados, homogêneos e estratificados (Fig. 25, 27). Cristais prismáticos presentes nas células subdivididas do parênquima axial.

Zollernia paraensis (pau-santo) - Cerne pretoesverdeado (Fig. 6). Camadas de crescimento demarcadas por finas linhas de parênquima marginal (Fig. 28). Vasos (Fig. 28) solitários e múltiplos de 2 a 

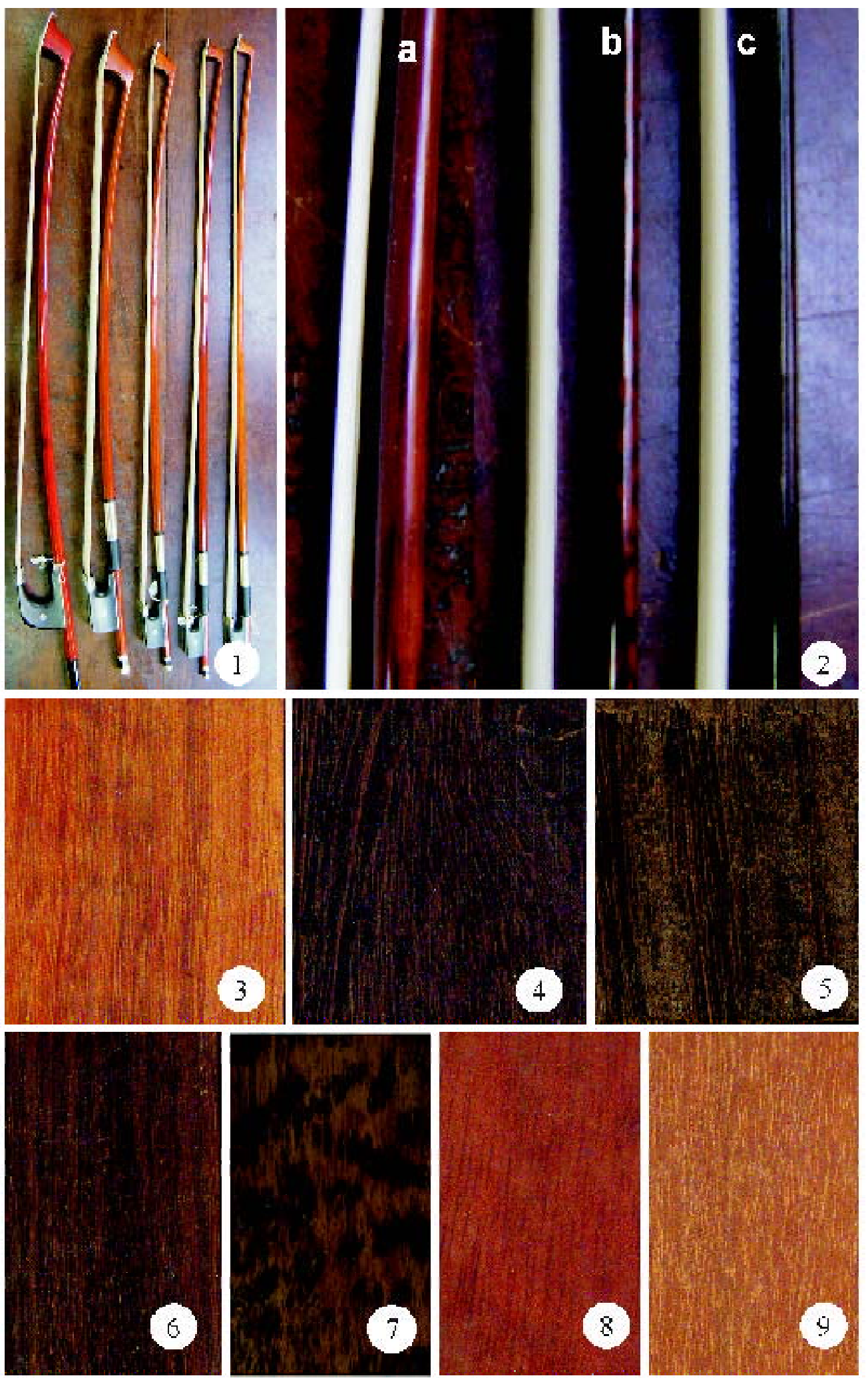

Figuras 1-2. Arcos de violino. 1. Caesalpinia echinata Lam. (pau-brasil), aspecto geral. 2. Detalhe de arcos de violino de outras madeiras: a. Brosimum paraense Huber (pau-rainha). b. Brosimum guianense (Aubl.) Huber. (pau-cobra). c. Manilkara elata (Fr. All.) Monac. (maçaranduba). Figuras 3-9. Aspecto longitudinal macroscópico das madeiras. 3. Caesalpinia echinata (pau-brasil). 4. Caesalpinia ferrea Mart. (pau-ferro). 5. Swartzia aptera D.C. (gombeira). 6. Zollernia paraensis Huber (pau-santo). 7. Brosimum guianense(paucobra). 8. Brosimum paraense (pau-rainha). 9. Manilkara elata (maçaranduba). 


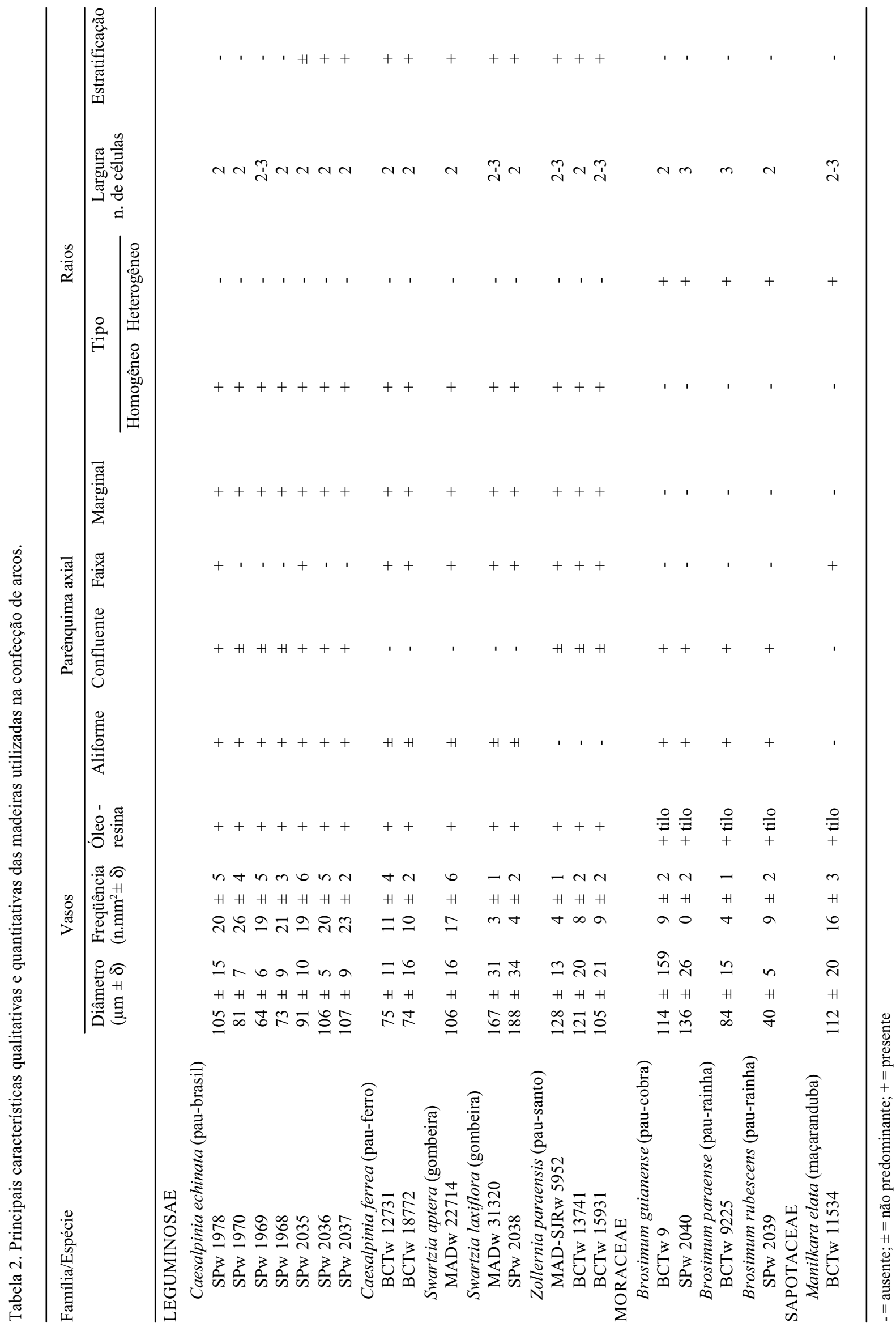



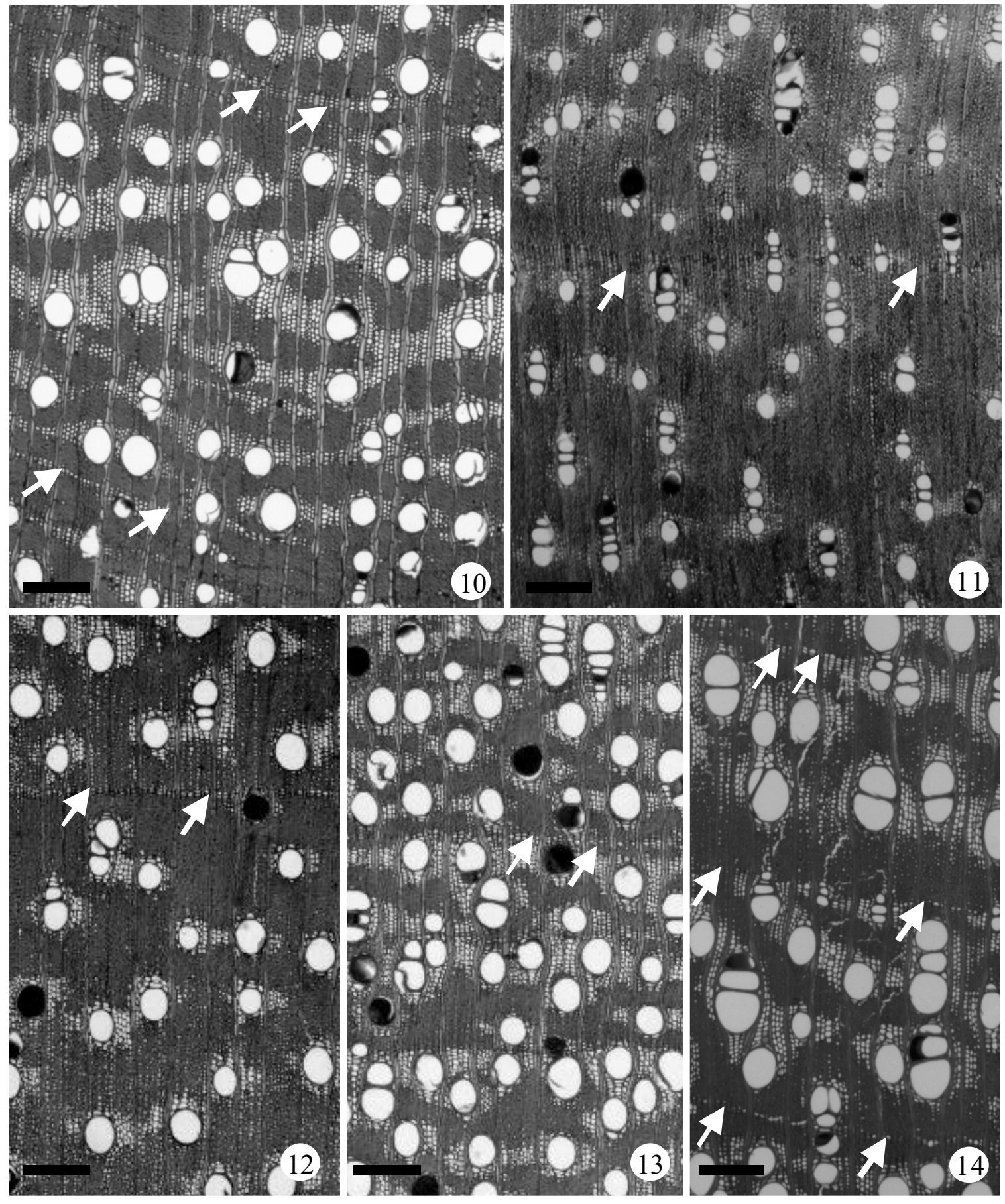

Figuras 10-14. Caesalpinia echinata Lam. (pau-brasil). Secção transversal. 10. SPw 1978, espécime nativo - Bahia, parênquima confluente formando faixas largas. 11. SPw 1970, espécime de reflorestamento - São Paulo, parênquima aliforme em curtas confluências. 12-14. Amostras de arcos. 12. SPw 2035, parênquima aliforme em curtas confluências. 13 -14. Parênquima confluente formando faixas largas; 13. SPw 2036. 14. SPw 2037. Setas $=$ parênquima marginal em linhas finas. Barra $=250 \mu \mathrm{m}$. 

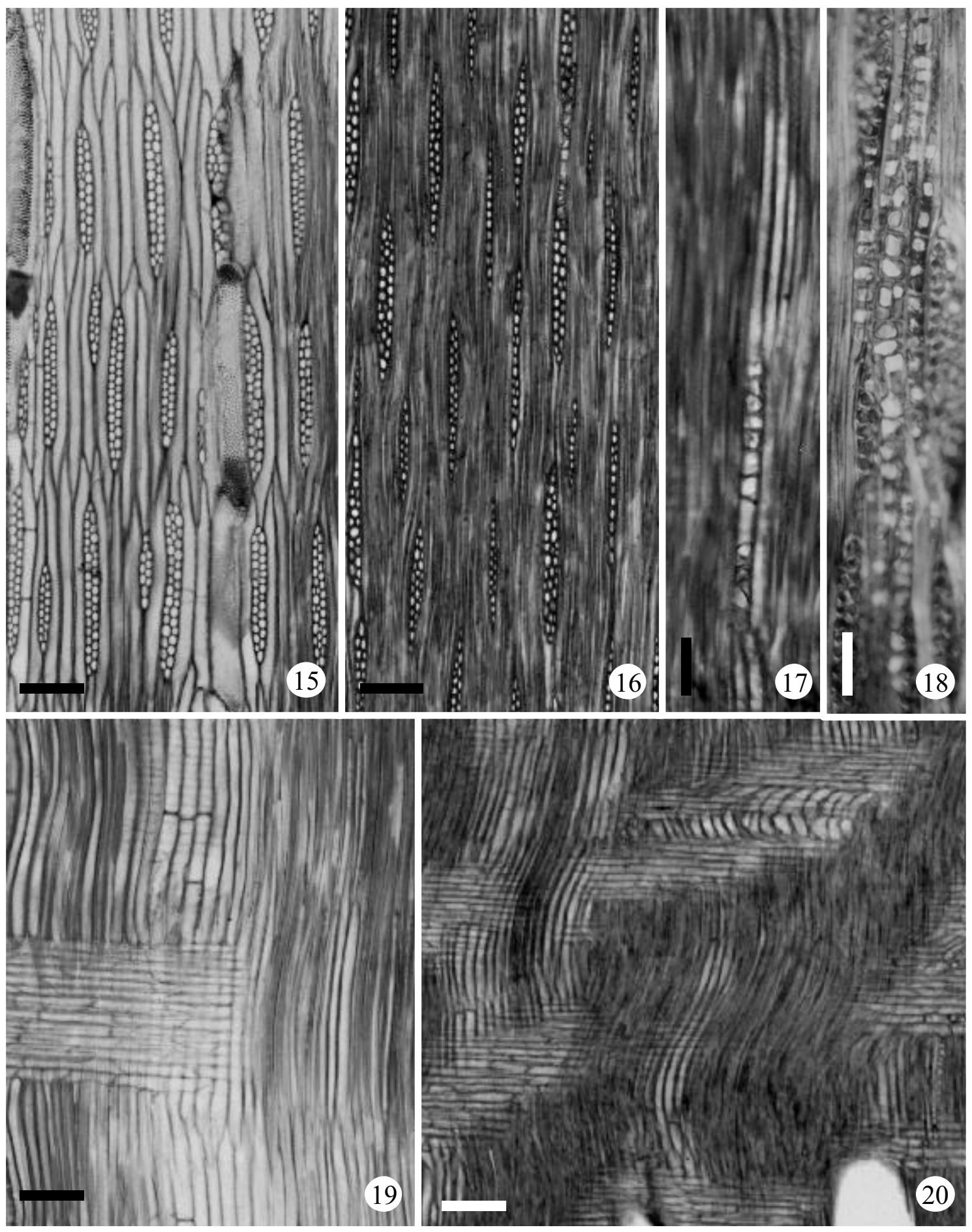

Figuras 15-20. Caesalpinia echinata Lam. (pau-brasil). 15-16. Secção tangencial. 15. SPw 2037 amostra de arco, raios bisseriados, homogêneos, estratificados. 16. SPw 1978, espécime nativo - Bahia, raios bisseriados, homogêneos, não estratificados. Barra $=100 \mu \mathrm{m}$. 17-18. Secção longitudinal, detalhe. 17. SPw 1970, espécime de reflorestamento - São Paulo, poucos cristais prismáticos em células subdivididas do parênquima axial. Barra $=75 \mu \mathrm{m}$. 18. SPw 1978, espécime nativo - Bahia, abundantes cristais prismáticos em células subdivididas do parênquima axial. Barra $=65 \mu \mathrm{m}$. 19-20. Secção radial. 19. SPw 2037, amostra de arco, raios homogêneos, grã reta ou linheira. 20. SPw 1978, espécime nativo - Bahia, raios homogêneos, grã irregular. Barra $=100 \mu \mathrm{m}$. 


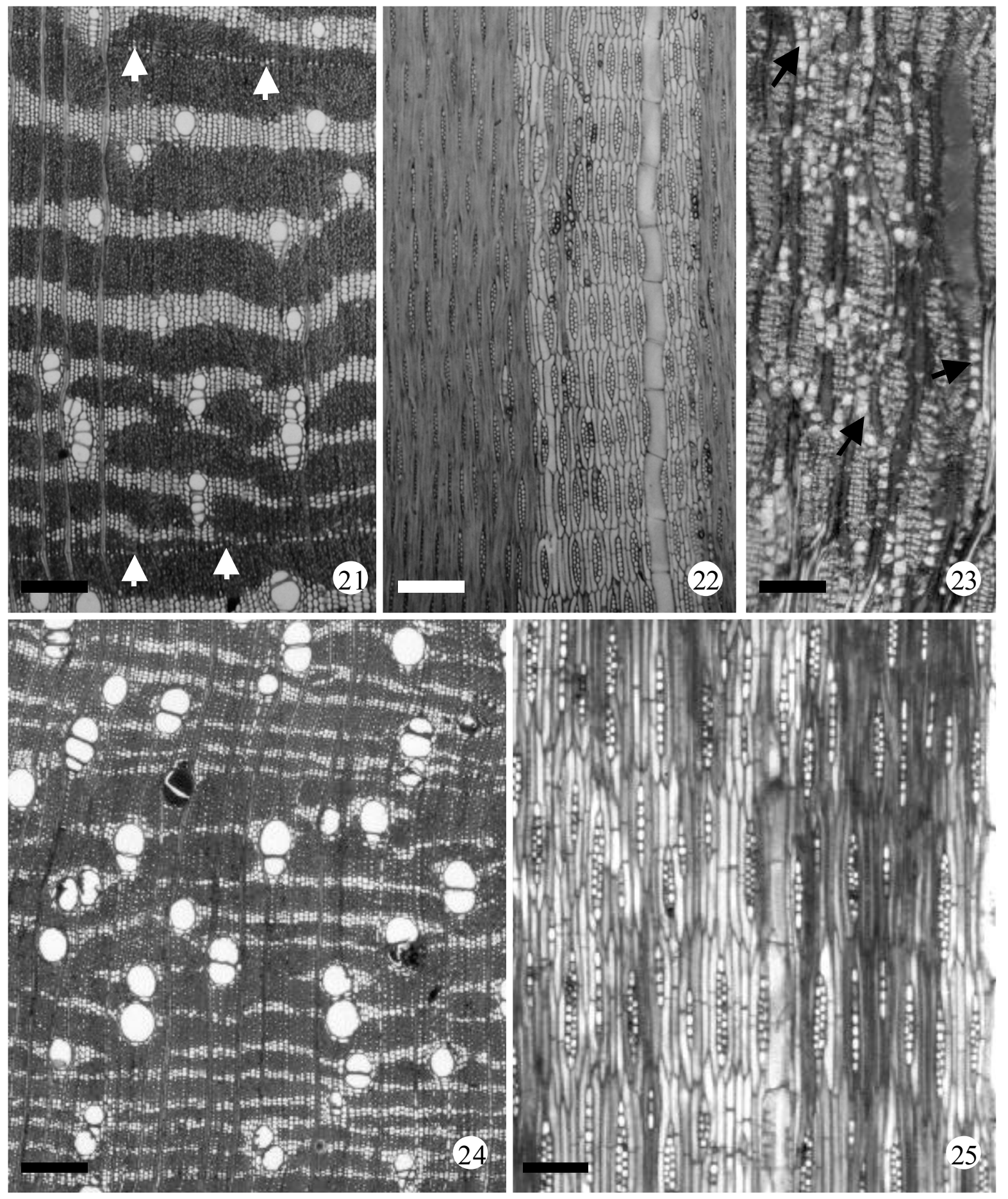

Figuras 21-23. Caesalpinia ferrea Mart. (pau-ferro). 21. Secção transversal, parênquima aliforme confluente, formando predominantemente linhas, setas = parênquima marginal em finas linhas. Barra $=250 \mu \mathrm{m}$. 22-23. Secção tangencial. 22. Raios homogêneos, estratificados. Barra $=250 \mu \mathrm{m}$. 23. Detalhe, abundantes cristais prismáticos em células subdivididas do parênquima axial. Barra $=100 \mu \mathrm{m}$. Figuras 24-25. Swartzia aptera D.C. (gombeira). 24. Secção transversal, parênquima aliforme confluente, formando predominantemente linhas. 25. Secção tangencial, raios bisseriados, homogêneos, estratificados. Barra $=250 \mu \mathrm{m}$. 

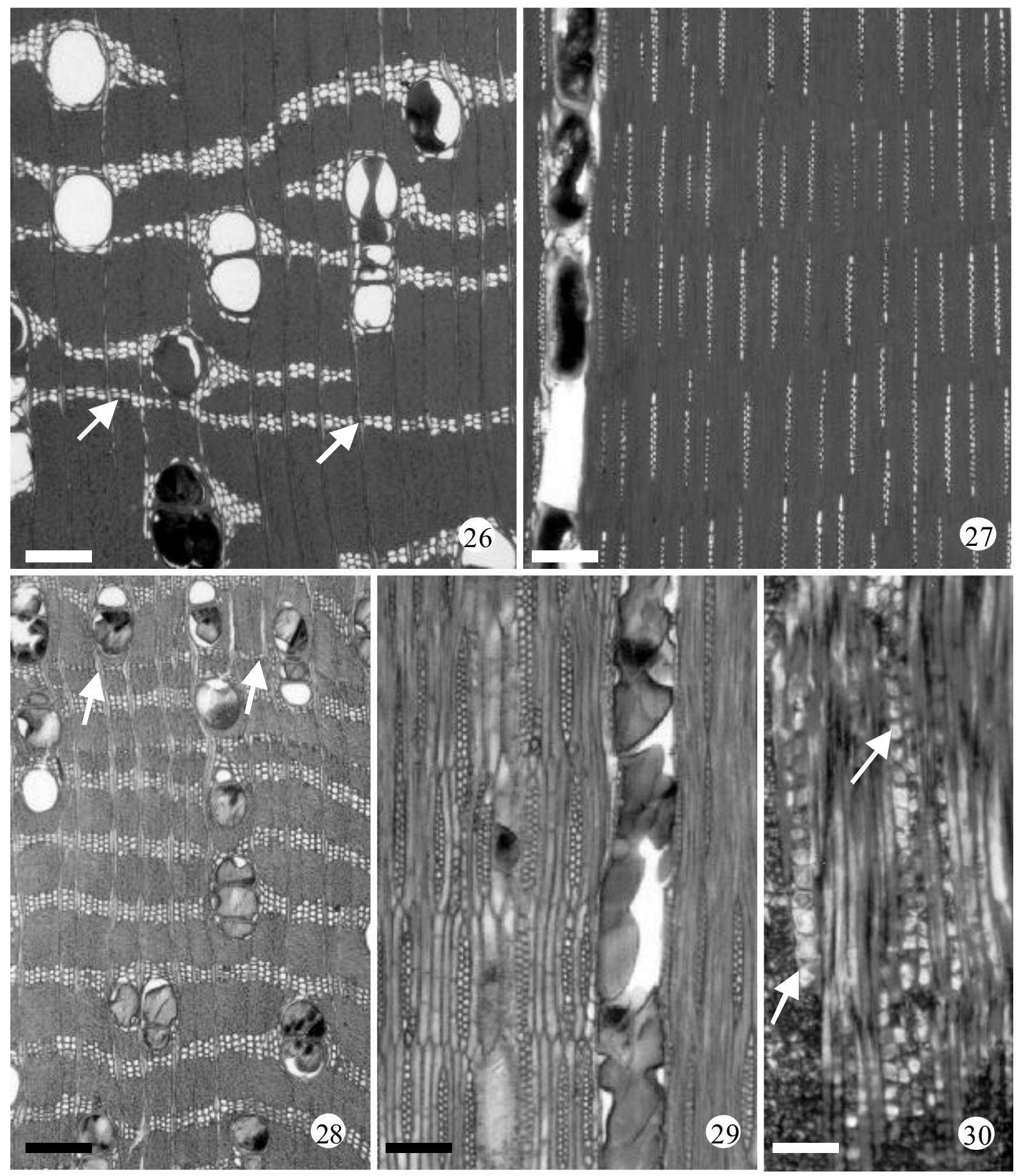

Figuras 26-27. Swartzia laxiflora Bongard ex Benth. (gombeira). 26. Secção transversal, parênquima aliforme confluente, formando predominantemente linhas, setas = parênquima marginal em finas linhas. 27. Secção tangencial, raios bisseriados, homogêneos, estratificados. Barra $=250 \mu \mathrm{m}$. Figuras 28-30. Zollernia paraensis Huber (pau-santo). 28. Secção transversal, parênquima confluente, formando predominantemente linhas, setas $=$ parênquima marginal em finas linhas. Barra $=250 \mu \mathrm{m}$. 29. Secção tangencial, raios bisseriados, homogêneos, estratificados. Barra $=250 \mu \mathrm{m}$. 30. Secção tangencial, detalhe, abundantes cristais prismáticos em células subdivididas do parênquima axial (setas). Barra $=65 \mu \mathrm{m}$. 

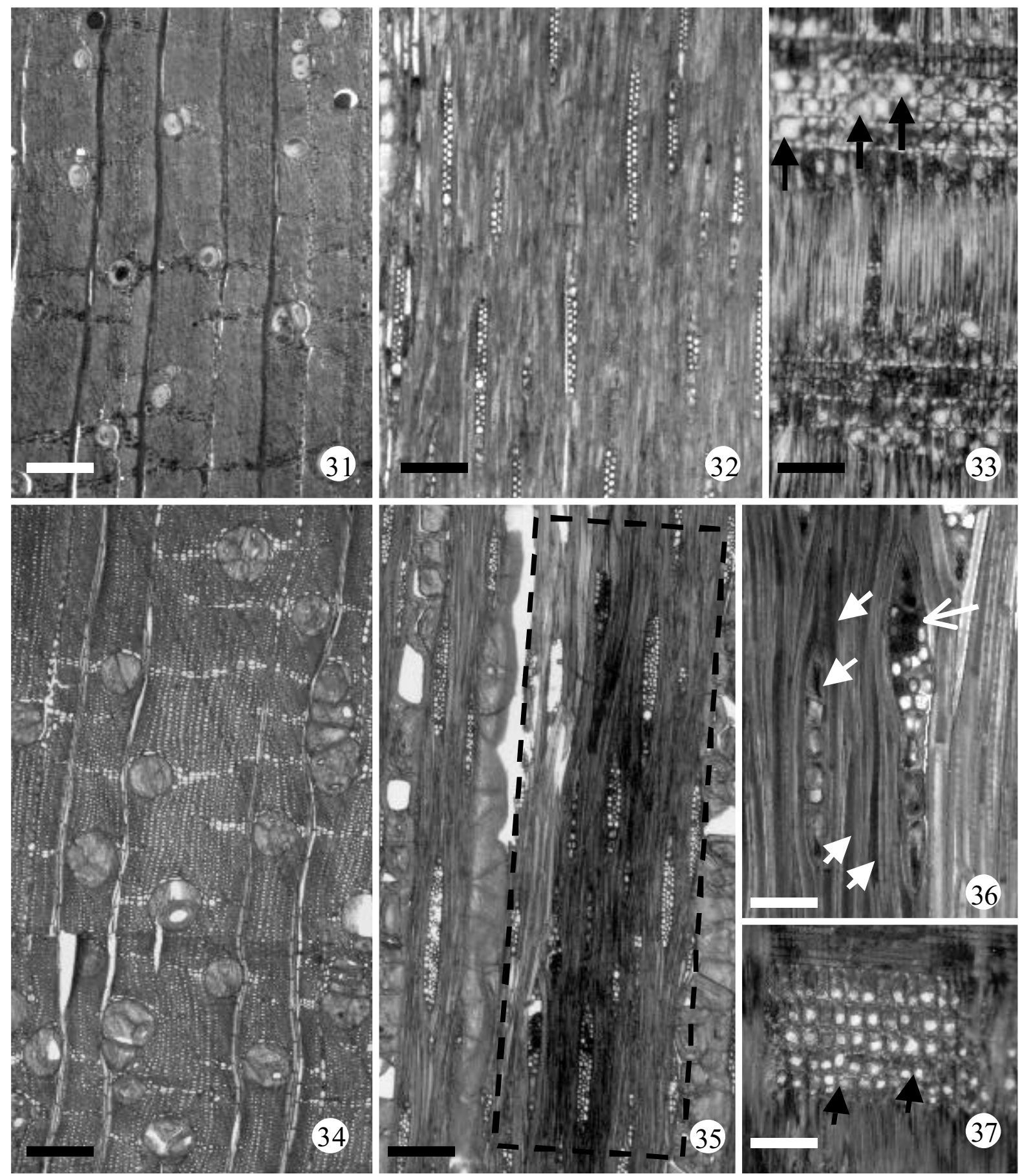

Figuras 31-33. Brosimum rubescens Taub. (Satiné) (pau-rainha). 31. Secção transversal, parênquima aliforme linear, vasos obstruídos por tilos esclerificados, contendo óleo-resina. Barra $=250 \mu \mathrm{m}$. 32. Secção tangencial, raios bisseriados, não estratificados. Barra $=250 \mu \mathrm{m}$. 33. Secção radial, detalhe, cristais prismáticos nas células marginais do raio (setas). Barra $=100 \mu \mathrm{m}$. Figuras 34-37. Brosimum guianense (Aubl.) Huber. (pau-cobra). 34. Secção transversal, parênquima aliforme linear, vasos obstruídos por tilos esclerificados. Barra $=250 \mu \mathrm{m}$. 35-36. Secção tangencial. 35. Raios não estratificados, com três células de largura, a porção pontilhada destaca a região da manchas escuras, correspondendo à deposição de óleo-resina na parede e no lume das fibras e das células radiais. Barra $=250 \mu$ m. 36 . Detalhe da porção pontilhada, evidenciando o lume das fibras e das células radiais com óleo-resina. 37. Secção radial. Detalhe dos cristais presentes nas células marginais dos raios (setas). Barra $=90 \mu \mathrm{m}$. 
3; obstruídos por óleo-resina; (62-)118(-166) $\mu \mathrm{m}$ diâm. tangencial; (3-)7(-11) por $\mathrm{mm}^{2}$; placa de perfuração simples (IAWA 1989). Fibras de paredes muito espessas. Parênquima confluente, predominantemente em linhas com 2 a 4 células de largura (Fig. 28). Raios bisseriados em BCTw 13741 (Fig. 29) e com 2 a 3 células de largura nos espécimes restantes; homogêneos e estratificados. Cristais prismáticos abundantes nas células subdivididas do parênquima axial (Fig. 30) e eventualmente observados nas células normais radiais.

Brosimum rubescens, Brosimum paraense (pau-rainha) - Cerne vermelho-coral (Fig. 2a, 8). Camadas de crescimento ausentes. Vasos (Fig. 31) solitários a múltiplos de 2 a 3; obstruídos por tilos esclerificados, contendo óleo-resina; (45-)84(-109) $\mu \mathrm{m}$ diâm. tangencial em B. paraense e (28-)40(-49) $\mu \mathrm{m}$ em B. rubescens (Fig. 31); (1-) 4 (-6) por $\mathrm{mm}^{2}$ em $B$. paraense e (7-)9(-11) em B. rubescens; placa de perfuração simples. Fibras de paredes muito espessas. Parênquima aliforme linear, formando curtas confluências. Raios bisseriados em Brosimum rubescens (Fig. 32) e com 3 células de largura em Brosimum paraense; heterogêneos com 2 a 4 células marginais quadradas a eretas; não estratificados. Cristais prismáticos presentes nas células radiais marginais (Fig. 33).

Brosimum guianense (pau-cobra) - Cerne vermelhoescuro com numerosas manchas negras agrupadas ou isoladas (Fig. 2b, 7). Camadas de crescimento ausentes. Vasos (Fig. 34) solitários a multiplos de 2 a 3; obstruídos por tilos esclerificados (Fig. 34-35); (70-)125(-185) $\mu \mathrm{m}$ diâm. tangencial; (5-)9(-13) por $\mathrm{mm}^{2}$; placa de perfuração simples. Fibras de paredes muito espessas. Parênquima aliforme linear, formando curtas confluências. Raios bisseriados em BCTw 9 e com 3 células de largura em SPw 2040; heterogêneos com 2 a 5 células marginais quadradas a eretas; não estratificados. Cristais prismáticos presentes nas células radiais marginais (Fig. 36). As manchas negras observadas na madeira são causadas pela deposição de óleo-resina na parede e lume das fibras e células radiais (Fig. 35, 36).

Manilkara elata (maçaranduba) - Cerne castanho escuro (Fig. 2c, 9). Camadas de crescimento, quando presentes demarcadas por zonas fibrosas. Vasos (Fig. 38) predominantemente múltiplos de 2 a 5; obstruídos por tilos, (66-)112(-146) $\mu \mathrm{m}$ diâm. tangencial; (11-)16(-22) por $\mathrm{mm}^{2}$; placa de perfuração simples. Fibras de paredes espessas. Parênquima em linhas finas numerosas e irregulares com duas células de largura (Fig. 38). Raios com 2 a 3 células de largura; heterogêneos com 1 a 3 células marginais quadradas a eretas; não estratificados (Fig. 39). Cristais prismáticos presentes nas células subdivididas do parênquima axial.

\section{Discussão}

Pau-brasil (Caesalpinia echinata) - De maneira geral, as características anatômicas observadas estão de acordo com o mencionado na literatura (Mainieri 1960; Mainieri et al. 1983; Détienne \& Jacquet 1983; Richter
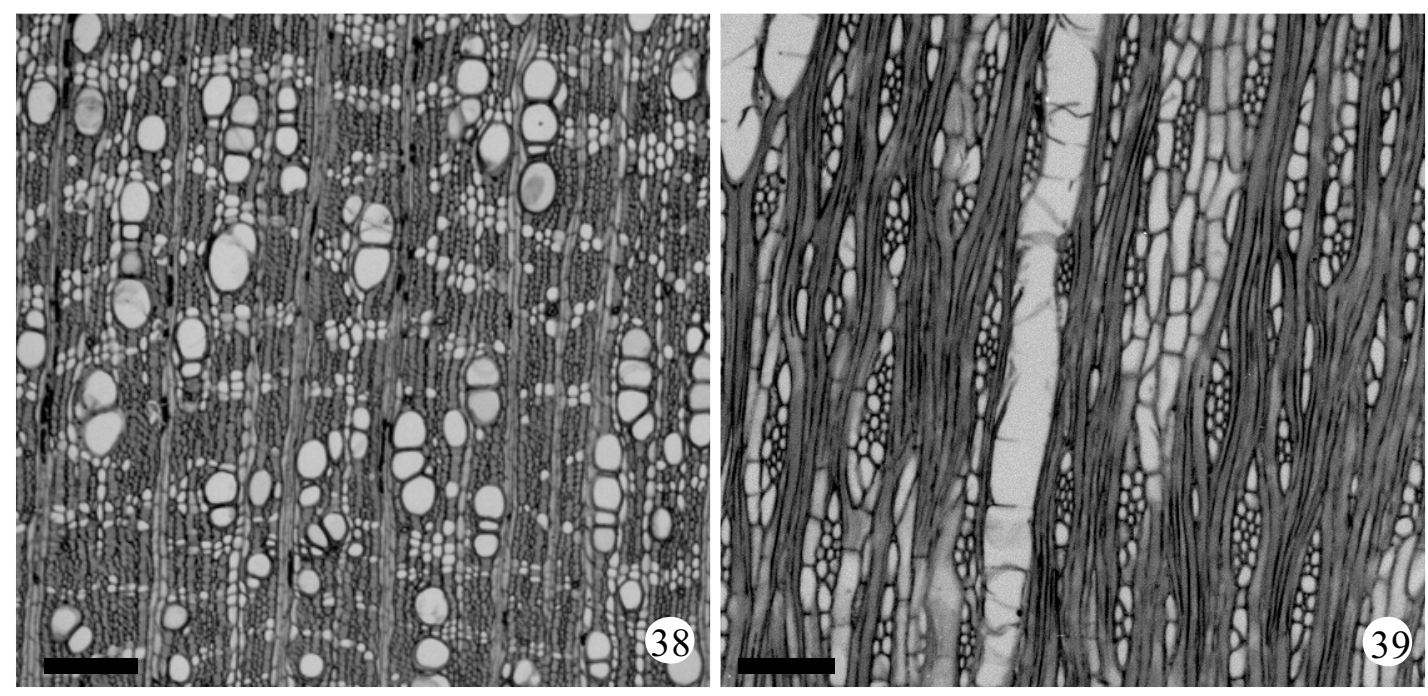

Figuras 38-39. Manilkara elata (Fr. All.) Monac. (maçaranduba). 38. Secção transversal, parênquima em linhas finas sinuosas e numerosas, vasos múltiplos predominantes. 39. Secção tangencial, raios heterogêneos com 1 a 3 células marginais quadradas/eretas, não estratificados. Barra $=250 \mu \mathrm{m}$. 
1988). Entretanto, uma análise comparativa qualitativa e quantitativa indica que existem variações de algumas características entre os diferentes indivíduos, que possivelmente estão relacionadas à fatores ambientais.

Uma destas características refere-se ao diâmetro dos vasos. No estudo do lenho, deve-se lembrar que a principal função deste tecido é a condução de água através, essencialmente, dos vasos. Segundo Zimmermann (1982), a condução eficiente e segura da água só é possível devido à estrutura tridimensional da madeira. $\mathrm{O}$ autor menciona que vasos de menor diâmetro e curtos são mais seguros na condução da água, enquanto vasos mais largos e longos são mais eficientes.

Vários estudos têm demonstrado que vasos de menor diâmetro, embora menos eficientes na condução de água, são mais seguros em ambientes secos, visto que permitem o desenvolvimento de maior pressão negativa antes do aparecimento de embolias, que tornam os vasos não funcionais (Zimmermann 1983; Baas et al. 1983; Wilkins \& Papassotiriou 1989; Lindorf 1994). A relação direta da diminuição do diâmetro dos vasos em espécies ou gêneros que crescem em ambientes com condições xéricas, também está associada à presença destas espécies em maiores latitudes, como o observado por Graaff \& Baas (1974), Baas et al. (1983), Dickison \& Phend (1985), Wilkins \& Papassotiriou (1989). Tal relação quanto ao diâmetro dos vasos pode ser observada nas amostras de C. echinata de procedência conhecida. A madeira coletada em Porto Seguro (BA), cujo clima é quente e super-úmido, sem um período de seca anual, apresenta vasos de maior diâmetro em relação às amostras coletadas em Mogi-Guaçu (SP). O clima, nesta região, caracteriza-se por apresentar um período anual seco e frio, localizando-se em maior latitude em relação à Porto Seguro (BA). Os vasos maiores observados no espécime de Porto Seguro (BA) promovem, potencialmente, maior eficiência na condução da água, em uma região onde a disponibilidade de água no solo e a evapotranspiração são maiores.

Além dos vasos, observa-se também variação no padrão de distribuição do parênquima axial, que é do tipo paratraqueal aliforme em todos os espécimes, apresentando maior ou menor grau de confluência, chegando a formar faixas. A abundância de parênquima, representada pelo parênquima em faixas largas, chama a atenção nas amostras procedentes da árvore da Bahia e nas de arcos de violino SPw 2036 e 2037. Segundo Wheeler \& Baas (1991), o parênquima paratraqueal é mais comum nas regiões tropicais do que nas temperadas. Tal tendência foi comprovada por Alves \& Angyalossy (2002), que analisaram a anatomia da madeira da flora arbórea de várias regiões brasileiras, demonstrando que o parênquima paratraqueal é característico em latitudes menores. Por meio de análise quantitativa, as autoras demonstram que o parênquima também é mais abundante em latitudes menores e, consequentemente, em ambientes mais quentes, o que é confirmado neste trabalho com a observação de parênquima mais abundante na amostra da Bahia, quando comparada com as amostras procedentes dos indivíduos de São Paulo. A relação direta da abundância do parênquima com latitudes menores também foi observada para espécies de outras floras por Baas e colaboradores (Baas 1973; Baas \& Zhang 1986; Baas \& Schweingruber 1987; Wheeler \& Baas 1991).

Considerando-se que o diâmetro dos vasos e a abundância de parênquima axial estão relacionados à latitude e a fatores climáticos, pode-se inferir que as amostras provenientes dos arcos de violino SPw 2036 e 2037 têm comportamento semelhante à amostra proveniente de Porto Seguro (BA), indicando que estas madeiras podem ter sido amostradas em indivíduos que crescem em região de menor latitude, com clima constantemente quente e úmido. Por outro lado, a amostra do arco SPw 2035 apresenta vasos de menor diâmetro e parênquima axial mais escasso, confluente sem formar faixas, características estas relaciondas a ambientes mais secos e de maior latitude, como o observado na amostra proveniente de São Paulo.

Apesar dos dados indicarem, para o pau-brasil (Caesalpinia echinata), tendência à correlação entre a latitude e os fatores climáticos com as características do vaso e do parênquima axial, é imprescindível, em trabalhos futuros, que haja uma abordagem anatômica com maior número de indivíduos, abrangendo os remanescentes das áreas de ocorrência natural da espécie, visando verificar se esta tendência é mantida.

Outra diferença encontrada nas amostras analisadas de pau-brasil refere-se à estratificação dos raios. Nas madeiras estratificadas, os elementos celulares do lenho podem estar organizados formando faixas horizontais regulares ou estratos. Segundo Burger \& Richter (1991), o efeito visual da estratificação (listrado de estratificação) pode ser normalmente evidenciado macroscopicamente. Embora a presença de estratificação seja característica importante usada na identificação de madeiras, observou-se, entre as amostras de pau-brasil, variações bastante acentuadas, desde presente a ausente. Tais variações são apontadas pontualmente na literatura 
(Mainieri 1960; Mainieri et al. 1983; Détienne \& Jacquet 1983; Richter 1988), sem que haja indicação da causa desta variação. Novamente, somente estudo amplo, levando-se em consideração a latitude, os fatores climáticos e os edáficos, poderá trazer uma possível resposta para tal variação.

Observou-se que o pau-brasil pode variar quanto à grã, de reta (ou linheira) a irregular. De acordo com Burger \& Richter (1991), o termo grã refere-se à orientação geral dos elementos verticais constituintes do lenho em relação ao eixo da árvore ou peça de madeira. Em decorrência do processo de crescimento, sob as mais diversas influências, há grande variação natural no arranjo e direção dos tecidos axiais, originando vários tipos de grã. A grã reta ou linheira é considerada o padrão normal, onde os tecidos axiais são orientados paralelamente ao eixo principal do tronco ou peça de madeira. Já as grãs irregulares incluem madeiras cujos elementos axiais apresentam variações de inclinação quanto ao eixo longitudinal do tronco ou peças de madeira. Para Richter (1988), uma das características necessárias para se obter um arco de violino de ótima qualidade é a presença de uma grã linheira na madeira empregada para tal. Jane (1962) afirma que irregularidades na grã afetam significativamente a velocidade de propagação das ondas sonoras na madeira, influenciando dessa forma suas propriedades de ressonância.

Conclui-se, neste trabalho, que as diferenças observadas no diâmetro dos vasos, na distribuição e quantidade de parênquima axial, na orientação dos elementos axiais e dos raios, são parâmetros que devem ser considerados quando se busca responder por que a qualidade madeira de pau brasil varia quando se utilizam diferentes amostras.

Madeiras substitutas do pau-brasil - Poucas madeiras podem ser consideradas como alternativas na confecção de arcos de intrumentos de corda. Segundo Richter (1988), a madeira para tal finalidade deve ser analisada sob cinco parâmetros: a) trabalhabilidade, com superfície lisa; b) orientação da madeira no caule (radial ou tangencial); c) textura fina dos elementos celulares axiais e grã linheira (reta); d) tamanho e posição dos defeitos da madeira; e) teste de dureza da madeira (macia ou dura), geralmente realizado pelo arqueteiro de forma manual.

Levando-se em consideração estes cinco parâmetros segundo Richter (1988), as madeiras a serem classificadas como de alta qualidade ("ouro") devem ser duras, cortadas no sentido radial do caule, sem defeitos e com grã linheira; as madeiras com qualidade inferior ("prata" e "bronze") têm exigências menores quanto a estes parâmetros.

Entretanto somente estes parâmetros não são suficientes para eleger uma madeira como substituta do pau-brasil. Deve-se considerar a densidade e as características anatômicas, que revelam, neste trabalho, a existência de diferenças e semelhanças entre a madeira do pau-brasil e a das oito espécies alternativas analisadas.

Todas as madeiras aqui analisadas apresentam densidade próxima ou maior que $1,0 \mathrm{~g} / \mathrm{cm}^{3}$ (Détienne \& Jacquet 1983; Mainieri et al. 1983; Mainieri \& Chimelo 1989; Richter 1988). A densidade da madeira está diretamente relacionada à quantidade de celulose que a constitui, sendo que o valor máximo que uma madeira pode ter corresponde à densidade da celulose, isto é, $1,5 \mathrm{~g} / \mathrm{cm}^{3}$. Assim, madeiras como o pau-brasil (Caesalpinia echinata), pau santo (Zollernia paraensis), pau cobra (Brosimum guianense) e paurainha (Brosimum paraense e B. rubescens), que apresentam fibras muito espessas, chegam a alcançar valores de até $1,30 \mathrm{~g} / \mathrm{cm}^{3}$. Fujiwara et al. (1991) e Fujiwara (1992), empregando análises de regressão múltipla e comparando 50 espécies de madeiras japonesas, confirmaram que a espessura da parede das fibras e a percentagem de material presente na parede têm forte influência na densidade da madeira. Os mesmos autores contataram que a densidade é fortemente relacionada ao volume dos raios e ao material das suas paredes. Por sua vez, Basson (1987) e Rao et al. (1997) relacionaram altas densidades com baixa freqüência de vasos.

Segundo Panshin \& De Zeeuw (1980), a densidade é uma propriedade física muito importante da madeira, uma vez que é um parâmetro que pode afetar outras propriedades. Altas densidades estão relacionadas também à redução no tamanho das células que compõem a madeira. Esta redução se expressa na textura fina da madeira, que corresponde a um dos cinco parâmetros desejados na madeira a ser usada para a confecção do arco.

Estudos realizados por E.S. Alves (dados não publicados) mostraram que os cristais de oxalato de cálcio são comuns entre as espécies brasileiras, confirmando a observação deste por Bass (1973) e Zhang et al. (1992), entretanto, os diferentes tipos são considerados caracteres diagnósticos na identificação de espécies lenhosas (IAWA Committee 1989). A presença de cristais prismáticos no parênquima axial e radial foi observada em todas as espécies avaliadas. 
As características comuns entre o pau brasil e as outras oito espécies alternativas são: os vasos de pequeno diâmetro, as fibras de paredes espessas a muito espessas, os raios compactados com poucas células de largura, a deposição de óleo-resina no lume das células, principalmente nos vasos e a presença de cristais.

Não são conhecidos os componentes químicos específicos dos extrativos da madeira, sendo comumentemente classificados como óleo-resina na literatura especializada em anatomia da madeira. Entretanto, para o pau-brasil, sabe-se que nos extrativos, entre outros, são encontradas a brasilina e a protosapanina $\mathrm{B}$, esta última correspondendo a $40 \%$ da quantidade total dos extrativos (Matsunaga et al. 1999; 2000a; 2000b).

Importantes experimentos realizados por Matsunaga e colaboradores (Matsunaga et al. 1996; 1999; 2000a; 2000b; Matsunaga \& Minato 1998; Minato et al. 1997) revelam que os extrativos (brasilina e protosapanina B), presentes no pau-brasil, afetam as propriedades vibracionais da madeira. Segundo os autores, a madeira de pau-brasil, quando comparada com outras, apresenta o menor valor de decaimento vibracional; um arco com baixo decaimento vibracional absorve menos energia vibracional quando a corda do instrumento é friccionada. Além disso, baixo decaimento vibracional permite ao músico "sentir" a fricção da crina com a corda, facilitando o manuseio do arco. Matsunaga et al. (1999; 2000a; 2000b) demonstram que os baixos valores de decaimento vibracional podem ser decorrentes da grande quantidade de brasilina e protosapanina $\mathrm{B}$, uma vez que ao extraí-las ocorreu aumento no decaimento vibracional da madeira de Caesalpinia echinata. Para confirmar a importância dos extrativos nas propriedades vibracionais do pau-brasil, os autores impregnaram a madeira de Picea sitchensis Carr. com tais extrativos e constataram redução no decaimento vibracional da mesma. Os autores concluíram que tal fato se deva à formação de ligações entre os componentes da madeira e os extrativos. A brasilina e a protosapanina $\mathrm{B}$ apresentam muitos grupos hidroxila que podem formar pontes de hidrogênio com os grupos hidroxila dos componentes da madeira.

Apenas com base na estrutura anatômica não é possível determinar se as madeiras analisadas, incluindose entre elas o pau-brasil, fornecerão arcos de maior ou menor qualidade, devendo-se associar as observações dos parâmetros apontados por Richter (1988), além de algumas propriedades físicas, mecânicas e acústicas da madeira. Entretanto, a estrutura anatômica tridimen- sional da madeira é parte fundamental na compreensão da qualidade final do arco e deve ser investigada com profundidade. Na prática, constatou-se que arcos de boa qualidade apresentam grã linheira e textura fina. Esta última característica decorre da menor proporção de vasos cujo diâmetro é reduzido, raios homogêneos e fibras com paredes espessas e/ou muito espessas. Assim, a relação entre a estrutura e a qualidade do arco está diretamente relacionada com as dimensões, a distribuição e a proporção das células do lenho.

Além do entendimento da variação das características anatômicas, apontadas neste trabalho, outros tópicos devem ser analisados, tais como os tipos e a quantidade de extrativos, o teor de lignina e características intrínsecas da parede das células.

E, mais importante ainda, deve-se considerar a sensibilidade, a experiência e a "arte" do arqueteiro, cuja capacidade em aproveitar ao máximo o potencial das madeiras tem papel importante na transformação da madeira bruta em arcos de grande beleza e qualidade.

\section{Agradecimentos}

À Fundação de Amparo à Pesquisa do Estado de São Paulo (FAPESP, Proc. 00/06422-4), ao Instituto de Pesquisas Tecnológicas do Estado de São Paulo IPT, pela concessão de amostras e lâminas de madeiras; ao Sr. Daniel Lombardi (Arcos Lombardi), pelas informações e concessão de madeiras utilizadas na confecção de arcos e das imagens representadas nas Figuras 1 e 2; aos Srs. Antonio C.F. Barbosa e Eduardo L. Longui, pela confecção de lâminas histológicas; à Dra. Rita de Cássia L.F. Ribeiro, pelas sugestões referentes ao texto.

\section{Referências bibliográficas}

Alves, E.S. \& Angyalossy, V. 2002. Ecological trends in the wood anatomy of some Brazilian species. 2. Axial parenchyma, rays and fibres. IAWA Journal 23: 391-418.

Aguiar, F.F.A. \& Pinho, R.A. 1996. Pau brasil - Caesalpinia echinata Lam. Folheto 18. São Paulo, Instituto de Botânica.

Baas, P. 1973. The anatomy of Ilex (Aquifoliaceae) and its ecological and phylogenetic significance. Blumea 21: 193-258.

Baas, P.; Werker, E. \& Fahn, A. 1983. Some ecological trends in vessel characters. IAWA Bulletin 4: 141-159.

Baas, P. \& Zhang, X. 1986. Wood anatomy of trees and shrubs from China. I. Oleaceae. IAWA Bulletin 7: 195-220.

Baas, P. \& Schweingruber, F.H. 1987. Ecological trend in the wood anatomy of trees, shrubs and climbers from Europe. IAWA Bulletin 8: 245-274. 
Basson, P. 1987. Some implications of anatomical variations in the wood of pedunculate oak (Quercus robur L.) including comparisons with comoron beech (Fagus sylvatica L). IAWA Bulletin 8: 149-166.

Bueno, E. 2002. Pau-brasil. São Paulo, Axis Mundi.

Burger, L.M. \& Richter, H.G. 1991. Anatomia da madeira. São Paulo, Nobel.

Détienne, P. \& Jacquet, P. 1983. Atlas d'identification des bois de l'amazonie et des régions voisines. Nogent-surMarne, Centre Technique Forestier Tropical.

Dickison, W.C. \& Phend, K.D. 1985. Wood anatomy of the Styracaceae: evolutionary and ecological considerations. IAWA Bulletin 6:3-22.

Eckblad, J.W. 1991. How many samples should be taken? BioScience 41: 346-348.

Fujiwara, S.; Sameshima, K.; Kuroda, K. \& Takamura, N. 1991. Anatomy and properties of japanese hardwoods I. Variation of fibre dimensions and tissue proportions and their relation to basic density. IAWA Bulletin 12: 419-424.

Fujiwara, S. 1992. Anatomy and properties of japanese hardwoods II. Variation of ray cells and their relation to basic density. IAWA Bulletin 13: 397-402.

Graaff. N.A. van der \& Baas, P. 1974. Wood anatomical variation in relation to latitude and altitude. Blumea 22: 101-121.

IAWA Committee. 1989. IAWA list of microscopic features for hardwood identification. E.A. Wheeler; P. Baas \& P. Gasson (eds.). IAWA Bulletin 10:219-332.

Jane, F.W. 1962. The structure of wood. London, Adam \& Charles Black.

Johansen, D.A. 1940. Plant microtechnique. New York, MacGraw-Hill Book Company.

Lewis, G.P. 1998. A revision of the Poicianella Erythrostemon Group. Kew, Royal Botanic Garden.

Lindorf, H. 1994. Eco-anatomical wood features of species from a very dry tropical forest. IAWA Journal 15: 361-376.

Mainieri, C. 1960. Estudo macro e microscópico de madeiras conhecidas por Pau-brasil. São Paulo, Publicação IPT 612.

Mainieri, C. \& Chimelo, J.P. 1989. Fichas de características da madeiras brasileiras. São Paulo, Publicação IPT 1791.

Mainieri, C.; Chimelo, J.P. \& Angyalossy, V. 1983. Manual de identificação das principais madeiras comerciais brasileiras. São Paulo, Promocet.

Matsunaga, M.; Sugiyama, M.; Minato, K. \& Norimoto, M. 1996. Physical and mechanical properties required for violin bow materials. Holzforschung 50: 511-517.

Matsunaga, M. \& Minato, K. 1998. Physical and mechanical properties required for violin bow materials II: Comparison of the processing properties and durability between pernambuco and substitutable species. Journal of Wood Science 44: 142-146.
Matsunaga, M.; Minato, K. \& Nakatsubo, F. 1999. Vibrational property changes of spruce wood by impregnation with water-soluble extractives of pernambuco (Guilandina echinata Spreng.). Journal of Wood Science 45: 470-474.

Matsunaga, M.; Obataya, E.; Minato, K. \& Nakatsubo, F. 2000a. Working mechanism of adsorved water on the vibrational properties of wood impregnated with extratctives of pernambuco (Guillandina echinata Spreng.). Journal of Wood Science 46: 122-129.

Matsunaga, M.; Sakai, K.M.; Kamitakahara, H.; Minato, K. \& Nakatsubo, F. 2000b. Vibrational property changes of spruce wood by impregnation with water-soluble extractives of pernambuco (Guillandina echinata Spreng.) II: structural analysis of extractives components. Journal of Wood Science 46: 253-257.

Minato, K.; Sakai, K.; Matsunaga, M.; \& Nakatsubo, F. 1997. The vibrational properties of wood impregnated with extractives of some species of Leguminosae. Mokuzai Gakkaishi 43: 1035-1037.

Nimer, E. 1989. Climatologia do Brasil. Rio de Janeiro, Instituto Brasileiro de Geografia e Estatística. $2^{\mathrm{a}}$. ed.

Panshin, A.J. \& De Zeeuw, C. 1980. Textbook of wood technology. New York, Mc Graw-Hill.

Pierce, R. 2002. The big issue. The Strad 8: 840-843.

Rao, R.V.; Aebischer, D.P. \& Denne, M.P. 1997. Latewood density in relation to wood fibre diameter, wall thickness, and fibre and vessel percentages in Quercus robur.IAWAJournal 18: $127-138$.

Retford, W.C. 1964. Bows and bow makers. Kent, Novello \& CompanyLimited.

Richter, H.G. 1988. Holz als Rohstoff für den Musikinstrumentenbau. Germany, Moeck Verlag Celle.

Vuono, Y.S.; Batista, E.A. \& Funari, F.L. 1986. Balanço hídrico na área da Reserva Biológica de Moji-Guaçu, São Paulo Brasil. Hohenea 13: 73-85.

Wheeler, E.A. \& Baas, P. 1991. A survey of the fossil record for dicotyledonous wood and its significance for evolutionary and ecological wood anatomy. IAWA Bulletin 12: 275-332.

Wilkins, A.P. \& Papassotiriou, S. 1989. Wood anatomical variation of Acaciamelanocalyx in relation to latitude. IAWA Bulletin 10: 201-207.

Zimmermann, M.H. 1982. Functional xylem anatomy of angiosperms trees. In: P. Baas (ed.). New Perspectives in Wood Anatomy. The Hague, Martinus Nijhoff Publishers.

Zimmermann, M.H. 1983. Xylem structure and the ascent of sap. Berlin, Springer Verlag. 